\title{
PRVI NALAZ CACOPSYLLA PULCHELLA (HEMIPTERA: PSYLLIDAE) U BOSNI I HERCEGOVINI
}

\section{FIRST RECORD OF CACOPSYLLA PULCHELLA (HEMIPTERA: PSYLLIDAE) IN BOSNIA AND HERZEGOVINA}

\author{
Osman MUJEZINOVIĆ ${ }^{1 *}$, Mirza DAUTBAŠIĆ ${ }^{1}$
}

\section{SAŽETAK}

U ovom radu je opisan prvi nalaz invazivne vrste (Cacopsylla pulchella) na području Bosne i Hercegovine. Ovo je potencijalno invazivna vrsta posebno za područje mediterana, odnosno južnih dijelova naše zemlje. Monofagna je vrsta, koja se hrani na judinom drvetu Cercis siliquastrum L. Značaj domaćina ovog štetnika u urbanim površinama, posebice u području Hercegovine te karakter invazivnosti, upućuju na ozbiljnost problema i potrebu dodatnih istraživanja bionomije i štetnosti.

KLJUČNE RIJEČI: invazivni insekt, strana vrsta, judino drvo, Cercis siliquastrum, hloroza listova.

\section{UVOD}

\section{INTRODUCTION}

Invazivne vrste insekata predstavljaju važne čimbenike koji na posredan i neposredan način uzrokuju poremećaje u prirodi i šumskim ekosustavima, čineći značajne ekonomske štete (Avtzis et al. 2018). Globalizacijom trgovine i međunarodnim putovanjima povećana je prijetnja za unos stranih i invazivnih vrsta (Roques at el. 2020). Prema istim autorima do 2019. godine značajan broj ovih insekata koji napadaju šumske i ukrasne vrste drveća i žbunja opisane su u Europi (njih ukupno 449). Promatrano, godišnje u Europi nađena je 6,1 nova vrsta za razdoblje od 2000. godine.

Cacopsylla pulchella Löw, 1877. je prvi put otkrivena na području Europe u Francuskoj 1964. godine (Hodkinson i White, 1979). Prema Mifsud et al, (2010) prirodno se nalazi u istočnom Mediteranu, gdje je strogo vezana za domaćina judino drvo Cercis siliquastrum L.. Kasnije je ova invazivna vrsta otkrivena i u drugim zemljama: Austrija, Velika Britanija, Grčka, Švicarska i Turska (Zeidan-Gèze i Burckhardt,
1998), Slovenija (Seljak, 2006), Mađarska (Ripka, 2008), Njamačka, Italija, Ukrajina (Burckhardt, 2010), Španjolska, Portugal (Sánchez, 2011), Srbija (Jerinić-Prodanović, 2011) Rusija (Balakhnina et al. 2015) i Hrvatska (Pernek et al. 2020). Ovo je monofaga vrsta, čiji je domaćin judino drvo Cercis siliquastrum (Burckhardt 1999) ali može biti na C. canadensis (Balakhnina et al. 2015). Štetno djelovanje insekta ogleda se u izraženoj hlorozi i sušenju biljaka (Rapisarda i Belcari 1997).

Cilj ovoga rada je bilo utvrđivanje prve prisutnosti ovog insekta morfološkim putem na istraživanim lokalitetima u Bosni i Hercegovini.

\section{MATERIJAL I METODE MATERIALS AND METHODS}

Istraživanja su provedena na pet (5) lokaliteta (tablica 1). Istim je obuhvaćeno da objekti istraživanja budu na području Bosne (1) lokalitet, koji ujedno predstavlja i konti-

\footnotetext{
1 Prof. dr. sc. Osman Mujezinović, Faculty of Forestry, University of Sarajevo, Zagrebačka 20, 71000 Sarajevo, Bosnia and Herzegovina. E-mail: osmansfs@yahoo.com ${ }^{2}$ Prof. dr. sc. Mirza Dautbašić, Faculty of Forestry, University of Sarajevo, Zagrebačka 20, 71000 Sarajevo, Bosnia and Herzegovina. E-mail: mirzad@bih.net.ba

${ }^{*}$ Autor za korespodenciju (corresponding author)
} 
Tablica 1. Lokaliteti prvog nalaza Cacopsylla pulchella u Bosni i Hercegovini Table 1. Localities of first record of Cacopsylla pulchella in Bosnia and Herzegovina

\begin{tabular}{|c|c|c|c|c|}
\hline Datum - Date & Lokalitet, ulica - Locality, street & Koordinate-Coordinates & $\begin{array}{l}\text { Cacopsylla pulchella Potvrđeno - } \\
\text { Cacopsylla pulchella confirmed }\end{array}$ & $\begin{array}{l}\text { Broj pregledanih stabala } \\
\text { The checked number of trees }\end{array}$ \\
\hline 03. 06. 2020. & $\begin{array}{c}\text { Sarajevo, } \\
\text { Zagrebačka. }\end{array}$ & $43^{\circ} 51^{\prime} 02^{\prime \prime} \mathrm{N} 18^{\circ} 24^{\prime} 01^{\prime \prime} \mathrm{E}$ & $\begin{array}{l}\mathrm{Ne} \\
\mathrm{No}\end{array}$ & 2 \\
\hline 04. 06. 2020. & $\begin{array}{c}\text { Mostar, } \\
\text { Španski trg, } \\
\text { Maršala Tita i } \\
\text { Nikole Šubića Zrinjskog. }\end{array}$ & $\begin{array}{l}43^{\circ} 20^{\prime} 37^{\prime \prime} \mathrm{N} 17^{\circ} 48^{\prime} 25^{\prime \prime} \mathrm{E} ; \\
43^{\circ} 20^{\prime} 09^{\prime \prime} \mathrm{N} 17^{\circ} 48^{\prime} 59^{\prime \prime} \mathrm{E} ; \\
43^{\circ} 20^{\prime} 31^{\prime \prime} \mathrm{N} 17^{\circ} 48^{\prime} 13^{\prime \prime} \mathrm{E} ;\end{array}$ & $\begin{array}{l}\mathrm{Da} \\
\text { Yes }\end{array}$ & $\begin{array}{l}6 \\
4 \\
5\end{array}$ \\
\hline 04. 06. 2020. & $\begin{array}{c}\text { Čapljina, } \\
\text { Fra Didaka Buntića. }\end{array}$ & $44^{\circ} 12^{\prime} 21^{\prime \prime N} ; 18^{\circ} 25^{\prime} 47^{\prime \prime} \mathrm{E}$ & $\begin{array}{l}\mathrm{Da} \\
\text { Yes }\end{array}$ & 4 \\
\hline 04. 06. 2020. & $\begin{array}{c}\text { Neum, } \\
\text { Put Svetog Ante. }\end{array}$ & $44^{\circ} 55^{\prime} 28^{\prime \prime} \mathrm{N} ; 17^{\circ} 37^{\prime} 23^{\prime \prime} \mathrm{E}$ & $\begin{array}{l}\mathrm{Da} \\
\text { Yes }\end{array}$ & 4 \\
\hline 05. 06. 2020. & $\begin{array}{c}\text { Ljubuški, } \\
\text { Vukovarska. }\end{array}$ & $43^{\circ} 11^{\prime} 55^{\prime \prime} \mathrm{N} ; 17^{\circ} 32^{\prime} 44^{\prime \prime} \mathrm{E}$ & $\begin{array}{l}\mathrm{Da} \\
\text { Yes }\end{array}$ & 3 \\
\hline
\end{tabular}

nentalni dio, te (4) druga objekta s područja Hercegovine, odnosno mediteranski dio.

S obzirom na to da istraživanjima nije utvrđivan intenzitet pojave insekta, pregledani su listovi s različitih pozicija, kako bi se samo utvrdila prisutnost njegove pojave.
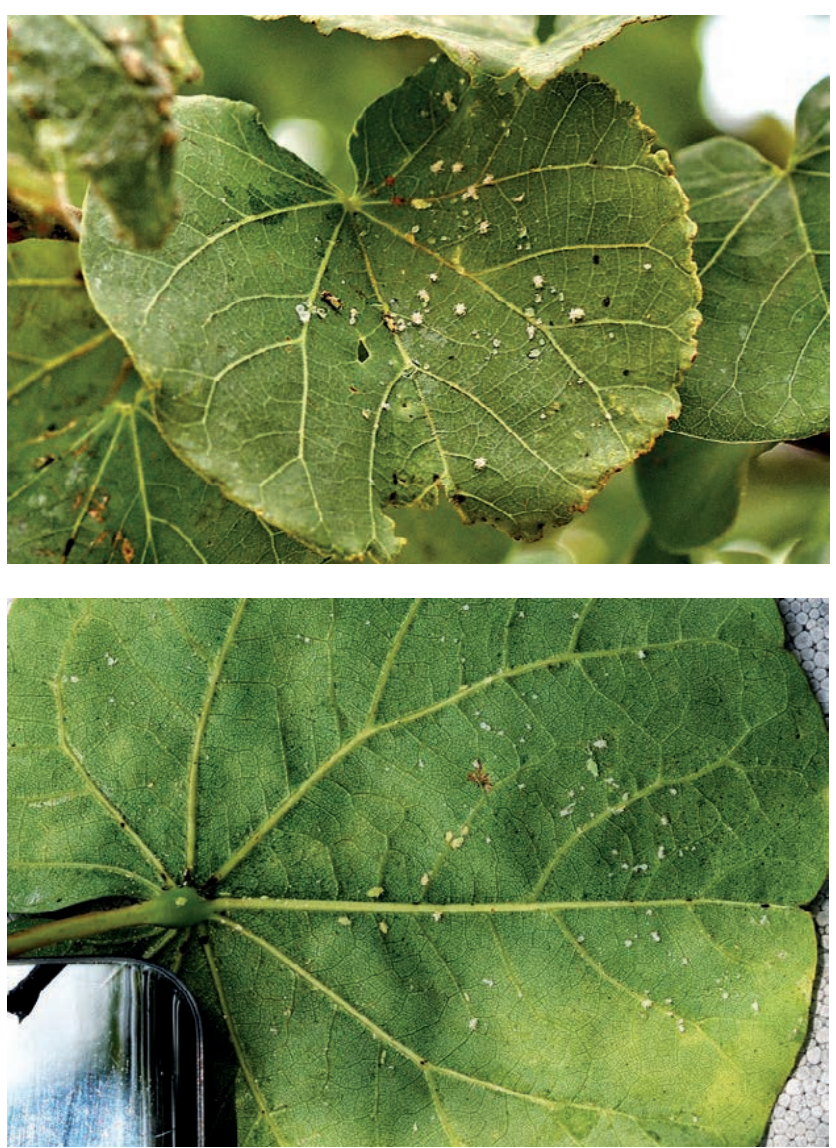

Slike 1 i 2. Imago Cacopsylla pulchella na licu judinog drveta i različiti stadiji nimfe na licu i naličju (foto Mujezinović)

Picture 1 and Picture 2. The adult Cacopsylla pulchella on the face of Judas tree of leaf and different stages of nymphs on the underside of Judas tree of leaf (photo Mujezinović)
Larve i imaga Cacopsylla pulchella sakupljeni i pohranjeni u 75\% etanol, te lisni materijal u herbarij radi kasnijih morfoloških analiza. Determinacija štetnika je obavljena u laboratoriju Katedre za zaštitu šuma i urbanog zelenila Šumarskog fakulteta Univerziteta u Sarajevu. Ista je provedena po ključevima Hodkinson i White (1979), Loginova (1964) i Burckhardt (1999). Razvojni stadiji insekta su fotografirani digitalnim fotoaparatom Nikon D7500, objektiv AF-S Micro NIKKOR 60 mm 1:2.8 G ED. Nakon provedenih morfoloških analiza primjerci štetnika pohranjeni su u hladnjaku. Ovim istraživanjem nije proučavana biologija vrste.

\section{REZULTATI}

U Bosni i Hercegovini, Cacopsylla pulchella utvrđena je na četiri (4) lokaliteta, od ukupno pet (5) istraživanih (tablica 1).

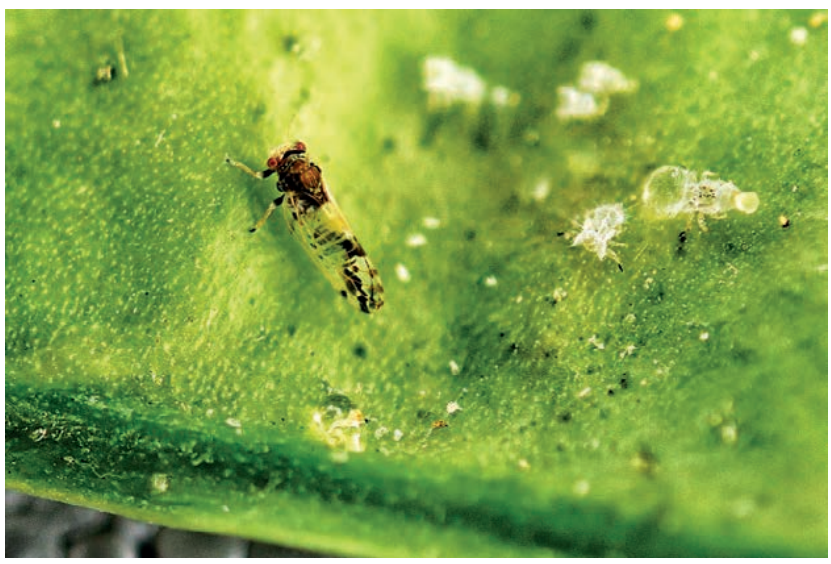

Slika 3. Imago Cacopsylla pulchella na plodu (mahuni) Cercis siliquastrum (foto Mujezinović)

Picture 3. The adult Cacopsylla pulchella on the Cercis siliquastrum of fruit (photo Mujezinović) 


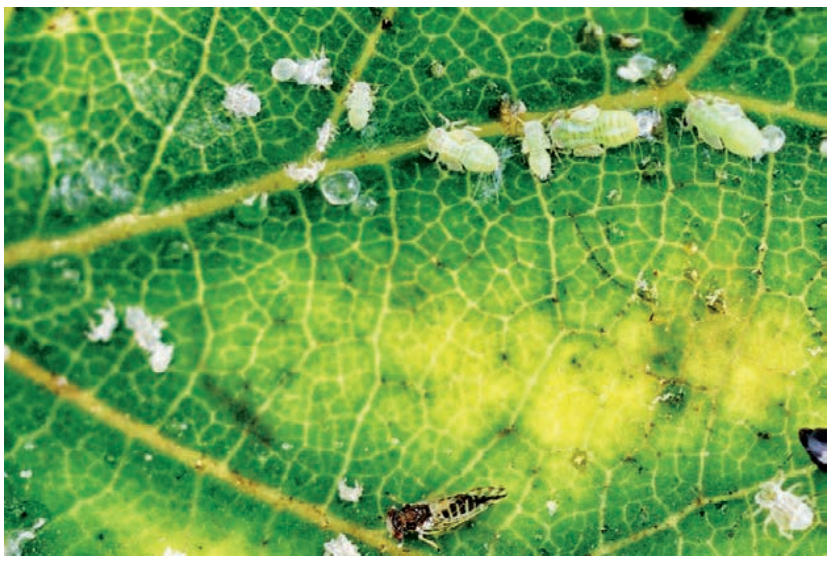

Slika 4. Klorotične i početak nekrotičnih mrlja na listu Cercis siliquastrum (foto Mujezinović)

Picture 4. The chlorotic and necrosis spots on the Cercis siliquastrum of leaf (photo Mujezinović)

Cacopsylla pulchella je prvi puta otkrivena u Bosni i Hercegovini na judinom drvetu Cercis siliquastrum.

Na napadnutim listovima, licu i naličju, uočavaju se određeni stadiji insekta, nimfe različitog stupnja razvoja i imaga (slike 1 - 3), te hloroza i nekroza listova (slika 4). Nije utvrđeno sušenje listova.

\section{RASPRAVA I ZAKLJUČCI DISCUSSION AND CONCLUSIONS}

Na osnovi predstavljenih rezultata istraživanja (tablica $1 \mathrm{i}$ slike 1 - 4) Cacopsylla pulchella je prisutna na području Bosne i Hercegovine. Prvi puta je utvrđena u maju 2020. godine na širem području Hercegovine, dok njezina prisutnost nije zabilježena u kontinentalnom dijelu (tablica 1). Prema (Mifsud et al., 2010) smatra se invazivnom vrstom na području Europe.

Listovi napadnutih biljaka, promatrajući iz daljine na sebi sadrže bjeličastosive mrlje, što ustvari predstavlja brojne jedinke insekta različitih razvojnih faza (slike 1 i 2 ). Imaga su zelenosmeđe boje. Na grudnom segmentu imaju narančaste pruge. Trbuh je tamnosmeđe boje (slika 3). na prednjim krilima su prisutne tamnosmeđe pjege. Nimfe imaju pet razvojnih stadija (Jerinić-Prodanović, 2011). Prema (Balakhnina et al. 2015) početni stadiji su žute boje (slika 2), a presvlačenjem se boja mijenja. U posljednjem stadiju razvoja ovog stadija je svjetlozelene boje sa poluprozirnim vrhovima krila (slika 4). Na području Švicarske (Burckhardt, 1999) i Srbije (Jerinić-Prodanović, 2011) utvrđeno je da insekt razvija jednu generaciju godišnje, dok su prema (Rapisarda i Belcari 1997) na području Italije pronađene tri generacije godišnje. Nimfe imaju pet razvojnih stadija (Jerinić-Prodanović, 2011). Početni stadiji su žute boje (slika 2), a presvlačenjem se boja mijenja. U posljednjem stadiju razvoja ovog stadija je svjetlozelene boje sa poluprozirnim vrhovima krila (slika 4).
Štetno djelovanje Cacopsylla pulchella ogleda se u umanjenju asimilacijske površine napadnutih listova, uzrokujući njihovu hlorozu i nekrozu (slika 4). Na ovaj način oštećeni listovi narušavaju estetski izgled stabala u urbanim površinama.

Na temelju prvog nalaza Cacopsylla pulchella može se zaključiti sljedeće:

- Štetnik je u Bosni i Hercegovini utvrđen u njenom mediteranskom dijelu 2020. godine;

- Prisutnost štetnika nije potvrđeno u kontinentalnom dijelu zemlje;

- Pronađena su imaga i nimfe ove vrste na listovima judinog drveta Cercis siliquastrum;

- Utvrđena štetnost ove vrste ogleda se u klorozi i nekrozi listova te umanjenju fotosintetske i estetske funkcije i

- Potrebna su dodatna istraživanja bionomije, štetnosti i širenja štetnika na stablima judinog drveta te ostalim domaćinima u Bosni i Hercegovini.

\section{LITERATURA}

REFERENCES

- 1. Avtzis, N D., Melika, G., Matošević, Dinka., Coyle, D. (2018): The Asian chestnut gall wasp Dryocosmus kuriphilus: a global invader and a successful case of classical biological control. Journal of Pest Science. Springer-Verlag GmbH Germany, part of Springer Nature 2018.

- 1. Balakhnina, IV., Labina, ES., Gnezdilov, VM., Pastarnak, IN. (2015): First Record of the Psyllid (Löw, 1877) (Hemiptera, Psyllidae) from Krasnodar Territory. Entomological Review 95(5): 612-614.

- 2. Burckhardt, D. (1999): Cacopsylla pulchella (Löw), eine Blattflohart des Judasbaums, auch in Basel (Hemiptera, Psylloidea). Mitt Entomol Ges Basel 49(2): 71-76.

- 3. Burckhardt, D. (2010): Fauna Europaea Hemiptera: Psylloidea Version 2.3.

- 4. Hodkinson, ID., White, IM. (1979): Handbooks for the Identification of British Insects. Royal Entomological Society of London, London, 2(5a): 1-98.

- 5. Jerinić-Prodanović, D. (2011): First record of Cacopsylla pulchella (Löw, 1877) (Hemiptera: Psyllidae) in Serbia. Acta Entomol Serb 16(1-2): 139-142.

- 6. Kenis, M., Auger-Rozenberg, MA., Roque, A., Timms, L., Péré, C., Cock, MJW., Settele, J., Augustin, S., Lopez -Vaamonde, C. (2009): Ecological effects of invasive alien insects. Biological Invasions 11: 21 - 45.

- 7. Loginova, MM. (1964): Classification of suborder Psyllinea - Psyllids or jumping plant-lice. Opredelitel nasekomih evropejskoj chasti SSSR, I, v pjati tomah. Nauka, Moskva- Leningrad, 437-482.

- 8. Mifsud, D., Cocquempot, C., Mühlethaler, R., Wilson, M., Streito, JC. (2010): Other Hemiptera Sternorrhyncha (Aleyrodidae, Phylloxeroidea, and Psylloidea) and Hemiptera Auchenorrhyncha. Chapter 9.4. In: Roques A et al. (eds) Alien terrestrial arthropods of Europe. BioRisk 4(1): 511-552. 
- 9. Pernek, M., et al. (2020): First Record of Cacopsylla pulchella (Hemiptera, Psyllidae) in Croatia, South-east European forestry, 11(1), str. 91-94.

- 10. Rapisarda, C. and Belcari, A. (1997): "Notes on Some Psyllids (Homoptera, Psylloidea) Infesting Urban Trees in Italy," Acta Horticult. 496, 155-164 (1997).

- 11. Ripka, G. (2008): Check list of the Psylloidea of Hungary (Hemiptera: Sternorrhyncha). Acta Phytopathol Hun 41(1): 121-142.

- 12. Roques, A., Shi, J., Rozenberg, MAA., Ren, L., Augustin, S., You-qing Luo, Y. (2020): Are Invasive Patterns of Non-native
Insects Related to Woody Plants Differing Between Europe and China? Front. For. Glob. Change.

- 13. Sánchez, I. (2011): Two exotic jumping plant-lice (Hemiptera: Psylloidea) new to mainland Portugal. Boletín de la Sociedad Entomológica Aragonesa 49: 324-324.

- 14. Seljak, G. (2006): An overview of the current knowledge of jumping plant-lice of Slovenia (Hemiptera: Psylloidea). Acta Entomol Sloven 14(1): 11-34.

- 15. Zeidan-Gèze, N., Burckhardt, D. (1998): The jumping plantlice of Lebanon (Hemiptera: Psylloidea). Rev Suisse Zool 105(4): 797-812.

\section{SUMIMARY}

This research is first record of Cacopsylla pulchella in Bosnia and Herzegovina. The insect was determined on a Judas tree Cercis siliquastrum at four localities in the june 2020 year.

The examined material is kept in the laboratory, Department of Forest Protection, faculty of Forestry, University of Sarajevo, Bosni and Herzegovina.

We have determined adults of $C$. pulchella an olive-drab or brownish green colour and nymphs green colour.

Since this is a foreign and potentially invasive species, its spread throughout the territory of Bosnia and Herzegovina can be expected, Herzegovina especially.

KEY WORDS: Cacopsylla pulchella, alien pest, Judas tree, Cercis siliquastrum, chlorotic spots, Bosnia and Herzegovina. 